\section{Acute Dyskinesias in Young Asthmatics Treated with Theophylline}

\author{
Michael R. Pranzatelli, MD*快, \\ Roger L. Albin, MD\$, and \\ Bruce H. Cohen, MDI
}

Two young children, 5 and 30 months of age, developed acute transient dyskinesias. The novel features of these patients were classic orobuccal-lingual dyskinesias, their young ages, and the association with asthma and theophylline. The movements resembled tardive dyskinesias of older patients on neuroleptics, but neither patient had any exposure to neuroleptic drugs. Choreiform movements were moderately severe and remitted several hours after discontinuation of theophylline or over days in the patient who remained on the drug. No symptomatic treatment of dyskinesia was required. Both infants otherwise had normal neurologic examinations with no clinical evidence of meningoencephalitis, seizures, or stroke. Both infants required hospitalization for respiratory distress, but not intensive care. The highest theophylline levels measured in these patients were 22 and $25 \mu \mathrm{g} / \mathrm{ml}$ and levels determined closest to the appearance of dyskinesias were lower. Urine toxicology screen for other drugs and routine blood work were normal. The infants, examined subsequently for 1 1/2-2 years for asthma, have demonstrated no reappearance of dyskinesias or other neurologic abnormalities. We propose an interaction of theophylline, hypoxemia, or other factors related to asthma in the pathophysiology of reversible dyskinesia in our patients.

Pranzatelli MR, Albin RL, Cohen BH. Acute dyskinesias in young asthmatics treated with theophylline. Pediatr Neurol 1991;7:216-9.

\section{Introduction}

Dyskinesias, or involuntary movements, include chorea, tremor, myoclonus, tics, and dystonia. Chorea refers to a "state of excessive, spontaneous movements, irregularly timed, nonrepetitive, randomly distributed, and abrupt in character" [1]. Chorea is generally slower than myoclonus, less stereotypic than tics, nonrhythmic unlike tremor, and unsustained in contrast to athetosis and dystonia. Facially, chorea may take on a more repetitive and stereotypic appearance, including mouthing, vacuous chewing, grimacing, sucking, puckering, blinking, or squinting [2]. In infants and children, however, facial dyskinesias are uncommon. For this reason and because of unusual characteristics and associations, we report 2 patients with primarily orofacial dyskinesias, a new neurologic complication of asthma treatment and we propose several possible mechanisms of pathogenesis.

\section{Case Reports}

Patient 1 . This $21 / 2$-year-old black male was 5 months of age when admitted for an initial episode of acute respiratory distress. Pregnancy, labor, and delivery had been uncomplicated. The patient had been completely well until he developed "bronchiolitis." The infant's respiratory distress was moderate with little respiratory accessory muscle use. He was treated intravenously with aminophylline (bolus), as well as steroids and ampicillin. The next day he developed acute orofacial dyskinesias of the type observed with phenothiazine administration; these episodes included dramatic tongue thrusting, lip pursing or puckering, and facial grimacing (Fig 1). Choreiform movements also manifested in upper limbs as repetitive hand opening and closing and extension of the arm in reaching movements. The infant was constantly fidgeting or squirming while held sitting. There was slight backward rocking. Total body movements were clearly excessive in the face, arms, and trunk, but not in the legs. There was grunting during the dyskinesias and dyspnea. The dyskinesias were of moderate severity, stereotypic, and resolved over several hours. The infant was alert and responsive and exhibited no signs of seizure activity; there was no previous family history of movement disorders or treatment with neuroleptics. The neurologic examination was otherwise unremarkable.

Sequential theophylline levels over the initial 48 hours are listed in Table 1 . There was no vomiting or seizures to suggest theophylline toxicity, but the drug was discontinued. Urine toxicology screen was negative for barbiturates, opiates, valium, phencyclidine, methadone, or amphetamine. Arterial blood gases were $\mathrm{pH} 7.2, \mathrm{PCO}_{2} 29$ $\mathrm{mm} \mathrm{Hg}, \mathrm{PO}_{2} 91 \mathrm{~mm} \mathrm{Hg}$, and bicarbonate $19 \mathrm{mmol} / \mathrm{L}$. Electrolytes, blood urea nitrogen, and glucose were normal. The hemogram revealed a mild microcytic (iron deficiency) anemia and hemoglobin electrophoresis was nor-
From the Departments of *Neurology, ${ }^{*}$ Pediatrics, and ${ }^{\ddagger}$ Pharmacology; George Washington University; Washington, DC; \$Department of Neurology; University of Michigan; Ann Arbor, Michigan;

IDepartment of Neurology; Cleveland Clinic Foundation; Cleveland. Ohio.
Communications should be addressed to:

Dr. Pranzatelli; Neurology Department;

Children's National Medical Center; 111 Michigan Avenue Northwest;

Washington, D.C. 20010.

Received November 27, 1990; accepted February 6, 1991. 


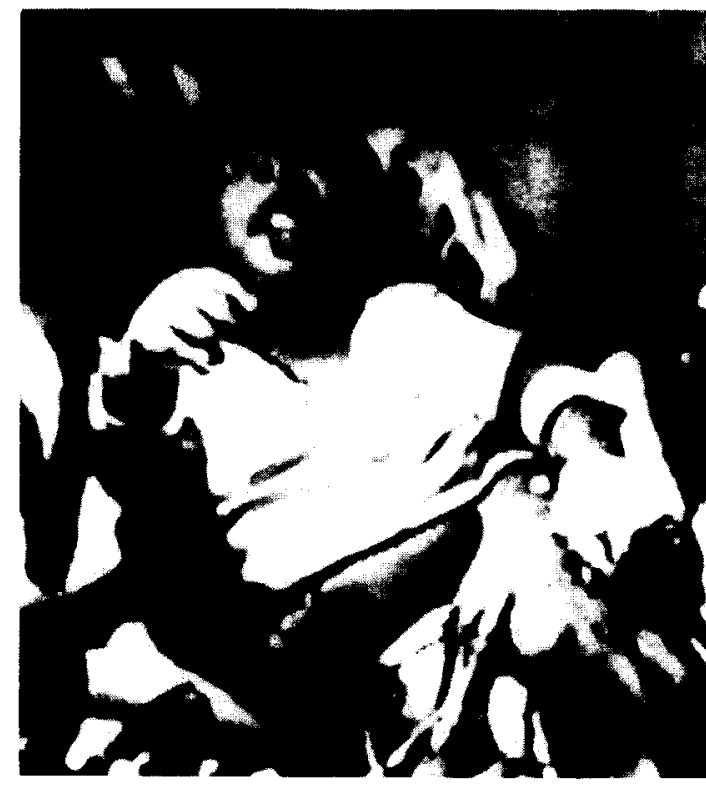

A

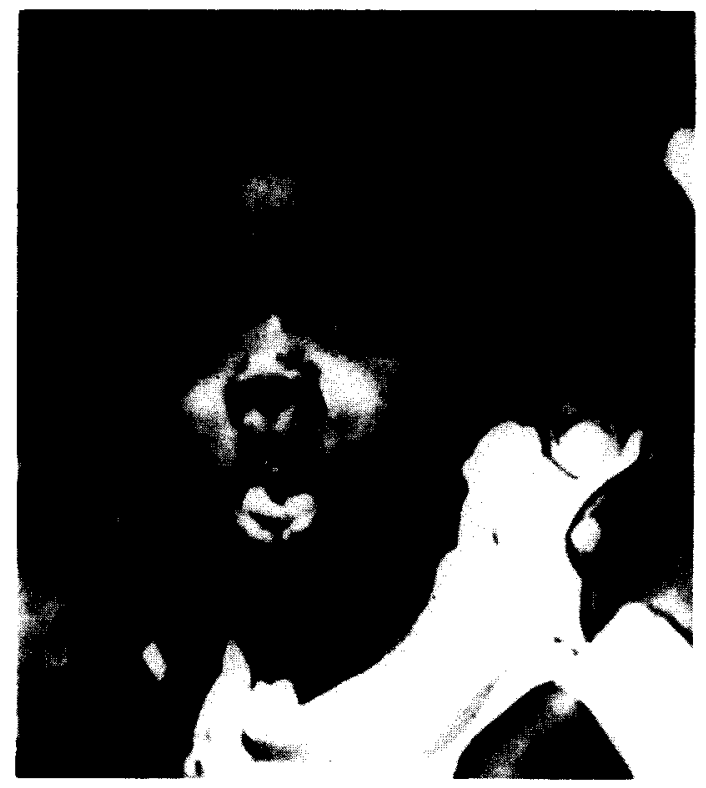

Figure 1. (A,B) Single frames from a videotape of Patient 1 while hospitalized. The infant is held on the lap of his mother

mal. The patient was discharged on amoxicillin and metaproterenol (Alupent ${ }^{(\circledR)}$ ), but has not continued with theophylline.

Two months later, the patient was readmitted for "bronchiolitis," but exhibited no neurologic abnormalities. The infant, subsequently examined over the next 2 years, developed asthma but has demonstrated no evidence of dyskinesias or other neurologic abnormalities.

Patient 2. This 4-year-old male was the product of an uneventful pregnancy ending in an emergency cesarean section because of fetal bradycardia to 90 . The amniotic fluid was meconium-stained, but no meconium was aspirated below the vocal cords. Apgar scores were 6 at 1 min and 7 at 5 min with a cord $\mathrm{pH}$ of 7.19. His post-delivery course was uneventful. At age 4 months, he suffered an upper respiratory infection complicated by wheezing. Subsequent upper respiratory infections were invariably accompanied by wheezing. At age 15 months, he developed bronchospasm with clinical and radiographic signs of right middle and lower lobe pneumonia and was treated successfully with amoxicillin and oral albuteral. His health and development otherwise were normal. At age 22 months, he suffered another asthma exacerbation and was placed on oral theophylline and nebulized mist treatments with albuteral/cromolyn. His theophylline dose was varied in an effort to obtain high-therapeutic levels, and he had serum levels between $6-25 \mu \mathrm{g} / \mathrm{ml}$.

The patient was in good health until 30 months of age when he was admitted for treatment of asthma and dehydration. He contracted a viral syndrome accompanied by diarrhea, fever, cough, and wheezing 5 days prior to admission. Three to 4 days prior to admission, he had unusual adventitious movements of the face. His theophylline was increased from $325 \mathrm{mg} /$ day to $350 \mathrm{mg} / \mathrm{day}$, and his mist treatments were increased to every 4-6 hours. Despite these measures, his bronchospasm worsened and he became increasingly tachypneic with retractions; oral amoxicillin was administered.

Physical examination on admission revealed a tired and slightly irritable child in moderate respiratory distress. His temperature was $39.5^{\circ} \mathrm{C}$, pulse $150 / \mathrm{min}$, blood pressure 90 by palpitation, and respiration $60 / \mathrm{min}$. His skin was warm and dry with somewhat dry mucous membranes. Pul-

Table 1. Serum theophylline concentrations and duration of dyskinesias*

\begin{tabular}{|c|c|c|c|}
\hline $\begin{array}{l}\text { Patient } \\
\text { Number }\end{array}$ & Dyskinesias & $\begin{array}{c}\text { Drug Level } \\
\quad(\mu \mathrm{g} / \mathrm{ml})\end{array}$ & $\begin{array}{c}\text { Time } \\
\text { Drawn }\end{array}$ \\
\hline \multirow[t]{5}{*}{1} & 0 & 13.7 & $\begin{array}{l}\text { Post-bolus } \\
\text { on admission }\end{array}$ \\
\hline & 0 & 22.0 & \\
\hline & + & 17.7 & \\
\hline & + & 22.0 & \\
\hline & 0 & 15.3 & \\
\hline \multirow[t]{5}{*}{2} & 0 & 6.0 & \\
\hline & 0 & 25.0 & \\
\hline & 0 & 8.9 & $\begin{array}{l}7 \text { days prior to } \\
\text { dyskinesias }\end{array}$ \\
\hline & + & 18.3 & On admission \\
\hline & + & 13.5 & IV aminophylline \\
\hline \multicolumn{4}{|c|}{$\begin{array}{l}\text { * The theophylline levels were drawn over } 48 \text { hours in Patient } 1 \text {, } \\
\text { whose dyskinesias lasted several hours, and over an } 8 \text {-month period } \\
\text { in Patient } 2 \text {, whose dyskinesias lasted } 10 \text { days. }\end{array}$} \\
\hline
\end{tabular}


monary examination revealed scattered wheezes, slightly prolonged expiratory phase, diffuse rhonchi, and rales at both bases. There were subcostal and intercostal retractions with mild nasal flaring and no grunting. The remainder of the physical examination was normal. Chest radiography demonstrated bilateral peribronchial thickening, streaky perihilar markings, and patchy airspace disease at the left base. Serum electrolytes and liver function tests were normal. Hemogram revealed hemoglobin $13.3 \mathrm{gm} / \mathrm{dl}$, hematocrit $38.4 \%$, leukocytes $3,200 \mathrm{~mm}^{3}$, and platelets $289,000 \mathrm{~mm}^{3}$. Room air oxygen saturation was $95 \%$; admission theophylline level was $18.3 \mu \mathrm{g} / \mathrm{ml}$.

Abnormal facial movements consisted of rhythmic thrusting of the tongue out of the mouth accompanied by an asymmetric facial grimace with the right corner of the mouth pulled up to the right. These facial movements occurred with variable frequency from several times per hour to once every few hours but were absent during sleep. The facial movements were strikingly reminiscent of tardive dyskinesia. There were no limb dyskinesias and no neuroleptics or antiemetics had ever been administered. Neurologic examination otherwise was normal.

The patient was then treated with intravenous fluids, steroids, aminophylline, and ampicillin, as well as terbutaline mist and acetaminophen. His blood cultures, latex agglutination for $S$. pneumoniae, and $H$. influenza were negative. He responded well to therapy and his respiratory distress rapidly diminished. One day after admission, his theophylline level was $13.5 \mu \mathrm{g} / \mathrm{ml}$ and he was discharged the following day. His abnormal facial movements decreased in frequency after admission and disappeared 1 week after discharge. They had been present for 10 days. He was discharged on theophylline at $350 \mathrm{mg} /$ day, prednisolone, and albuteral/cromolyn mist treatments. In the 18 months since his admission, there has been no recurrence of abnormal movements despite a few asthmatic attacks of lesser severity. He has remained on theophylline until the past 6 months. His development has been normal.

\section{Discussion}

Our patients had a movement disorder resembling tardive dyskinesia which has not been reported in young children or described in the absence of neuroleptic drugs. Tardive dyskinesia, a term used for dyskinesias associated with neuroleptics, is more stereotyped than chorea and includes orofacial (bucco-linguo-masticatory) dyskinesias, choreiform distal limb movements ("piano playing"), truncal dyskinesias ("body rocking"), akathisia (subjective sensation of restlessness), and respiratory dyskinesias [3]. Therefore, these patients may contribute to our understanding of the pathogenesis of tardive dyskinesia. No symptomatic treatment of dyskinesia was required, even though the choreiform movements were moderately severe. Although we recommended that theophylline be discontinued during the dyskinesia, the abnormal movements of the patient who remained on the drug also resolved along with the asthmatic attack. This syndrome is distinct from other complications of the treatment of asthma associated with toxic drug levels and appears to be benign.

The differential diagnosis of facial chorea begins with the exclusion of other facial dyskinesias, such as tremor, myoclonus, tics, and dystonia [4]. The orofacial movements in our patients were distinctive. There was no evidence for other etiologies of facial chorea, such as hereditary, drug or toxic, metabolic, endocrine, nutritional, infectious, immunologic, or cerebrovascular disorders [2]. Although it is prominent in infancy, physiologic chorea does not usually involve the face and should have appeared at other times beside the acute asthmatic episodes in our patients [2]. Our patients were not exposed to neuroleptics, anticholinergics, tricyclic antidepressants, antihistamines, or other drugs known to induce chorea [2]. Static, mild choreiform movements often accompany attention deficit disorder, but dyskinesias in our patients differed because they were severe and transient, while other neurologic deficits were absent. Similarly, "extrapyramidal cerebral palsy" typically presents after the first year of life, is more choreoathetoid, and is not transient [5]. Other choreic disorders can be excluded in our patients in the absence of chronicity, associated medical, neurologic, or developmental abnormalities, positive family history, or early age of onset [6].

We speculate that theophylline in the setting of hypoxemia or other factors induced the dyskinesias in our patients. Theophylline alone is an insufficient cause because 1 patient remained on the drug while the dyskinesias resolved. Theophylline toxicity is unlikely because seizures, encephalopathy, and tremor-but not other dyskinesias - have been reported with toxic levels [7]; Patient 2 had had higher theophylline levels previously without precipitating dyskinesias and neither patient had very high drug levels. Pharmacokinetic interactions with other drugs would not explain the onset of dyskinesias in Patient 2 prior to the administration of other drugs. Various methylxanthines, other than theophylline, precipitate paroxysmal dystonic choreoathetosis, which our patient did not have [8-10]. One mechanism that could explain the participation of theophylline, hypoxemia, stress, or other factors related to asthma in the pathophysiology of these dyskinesias is excessive striatal dopaminergic activity, which has been implicated in chorea. Oral dyskinesias can be induced experimentally by putative $D_{1}$ dopamine receptor agonists and potentiated by $\mathrm{D}_{2}$ agonists $[11,12]$. Striatal $D_{1}$ - and $D_{2}$-receptors, functionally interdependent and reciprocally coupled to adenylate cyclase [11], increase in density in animals withdrawn from chronic neuroleptic treatment thus suggesting dopamine receptor supersensitivity as the mechanism of tardive dyskinesias [13]. Theophylline could interact with striatal dopaminergic mechanisms by direct activity at dopamine receptors or blockade of the tonic influence of adenosine on dopaminergic mechanisms through pre- and post-synaptic actions [14] mediated by adenosine receptors on neurons that 
synapse with dopamine-containing neurons $[14,15]$. Theophylline is a potent, nonselective antagonist at $\mathrm{A}_{1}$ and $A_{2}$ receptors found in striatum; therefore, 1 or both types of adenosine receptors may be involved in a purino-dopaminergic interaction $[15,16]$. The adenylate cyclase pool shared by dopamine and adenosine is another potential site of purino-dopaminergic interaction [17]. Alternatively, theophylline may have modulated cerebral blood flow in the basal ganglia during hypoxemia by blocking vascular adenosine receptors $[18,19]$. Theophylline opposes the selective cerebral vasodilatation in the caudate nucleus induced by adenosine at $\mathrm{A}_{2}$ receptors, especially during hypoxia [20], and such a transient regional ischemia in the basal ganglia may be relevant to our patients, as it is in the chorea of systemic lupus erythematosus and polycythemia vera [3]. Theophylline-induced blockade of adenosine's protective effect against glutamate-mediated neuronal injury in hypoxic-ischemic events is possible, but unlikely, because our patients did not appear to have severe hypoxic-ischemic events $[21,22]$.

Our report is apparently the first to document acute, transient orofacial dyskinesias in asthmatic infants. A clinically similar movement disorder has been described recently in premature infants with severe bronchopulmonary dysplasia [23]. Although chronic hypoxemia was invoked as the pathogenesis of dyskinesias in these infants, they were also on therapeutic levels of theophylline for recurrent bronchospasm. Our patients did not share the chronically severe respiratory disease but were also treated with theophylline. At present, the relative contribution to the dyskinesias of theophylline versus hypoxemia, stress, or other factors related to asthma cannot be determined. It also is unknown whether the transient infantile dyskinesias we described are uncommon or merely unrecognized.

We thank Delores Wider for word processing assistance.

\section{References}

[1] Lakke PWF. Classification of extrapyramidal disorders. J Neurol Sci 1981;51:311-27.

[2] Kurlan R, Shoulson I. Differential diagnosis of facial chorea. In: Jankovic J, Tolosa E, eds. Advances in neurology, vol 49. Facial dyskinesias. New York: Raven Press, 1988;225-37.

[3] Goetz CG. Diagnosis of tardive dyskinesia. Clin Neuropharmacol 1983;6:101-7.
[4] Padberg GW, Bruyn GW. Chorea-differential diagnosis. In: Vinken PJ, Bruyn GW, Klawans HL, eds. Handbook of clinical neurology, vol 5. Extrapyramidal disorders. Amsterdam: Elsevier Science Publishers, 1986;549-64.

[5] Crothers B, Payne RS. The natural history of cerebral palsy. Cambridge: Harvard University Press, 1959;1-299.

[6] Pincus JH, Chutorian A. Familial benign chorea with intention tremor. J Pediatr 1967;70:724-9.

[7] Paloucek FP, Rodvold KA. Evaluation of theophylline overdoses and toxicities. Ann Emerg Med 1988;17:135-44.

[8] Nakano T, Kondo K, Oguchi K, Yanagisawa N, Nakano T. A late onset case of paroxysmal dystonic choreoathetosis induced by caffeine and aminophylline. Rinsho Shinkeigaku 1983;23:199-203.

[9] Jankovic J. Cranial-cervical dyskinesias: An overview. In: Jankovic J, Tolosa E, eds. Advances in neurology, vol 49: Facial dyskinesias. New York: Raven Press, 1988;1-14.

[10] Lance JW. Familial paroxysmal dystonic choreoathetosis and its differentiation from related syndromes. Ann Neurol 1977;2:285-93.

[11] Clark D, White FJ. Review: $D_{1}$ dopamine receptor - the search for a function: A critical evaluation of the $D_{1} / D_{2}$ dopamine receptor classification and its functional implications. Synapse 1987;1: $347-88$.

[12] Rosengarten HJ, Schweitzen W, Friedhoff AJ. Induction of oral dyskinesias in naive rats of D-1 stimulation. Life Sci 1983;33: 2479-82.

[13] Jenner $P$, Marsden $C D$. Adaptive changes in brain dopamine function as a result of neuroleptic treatment. In: Jankovic J, Tolosa E, eds. Advances in neurology, vol 49: Facial dyskinesias. New York: Raven Press, 1988;417-31.

[14] Criswell H, Mueller RA, Breese GR. Assessment of purinedopamine interactions in 6-hydroxy-dopamine-lesioned rats: Evidence for pre- and postsynaptic influences by adenosine. J Pharmacol Exp Ther 1988;244:493-500.

[15] Wojcik WJ, Neff NH. Differential location of adenosine $A_{1}$ and $A_{2}$ receptors in striatum. Neurosci Lett 1983;41:55-60.

[16] Fastbom J, Pazos A, Probst A, Palacios JM. Adenosine A, receptors in the human brain: A quantitative autoradiographic study. Neuroscience 1987;22:827-39.

[17] Abbracchio MP, Colombo F, Di Luca M, Zaratin P, Cattabeni F. Adenosine modulates the dopaminergic function in the nigro-striatal system by interacting with striatal dopamine dependent adenylate cyclase. Pharmacol Res Commun 1987;19:275-86.

[18] Hardebo JE, Kahrstrom J, Owman C. $P_{1}$ - and $P_{2}$-purine receptors in brain circulation. Eur J Pharmacol 1987;144:343-52.

[19] Williams M, Jarvis MF. Adenosine antagonists as potential therapeutic agents. Pharmacol Biochem Behav 1988;29:433-41.

[20] Puiroud S, Pincad E, Seylaz J. Dynamic cerebral and systemic circulatory effects of adenosine, theophylline and dipyridamole. Brain Res 1988;453:287-98.

[21] Fowler JC. Adenosine and its role in ischemia/hypoxia. Soc Neurosci Abstr 1989;15:42.

[22] Globus MYT, Dietrich WD, Busto R, Valdes L, Ginsberg MD. Combined treatment with dopamine and NMDA receptor antagonists protects against ischemic damage. Soc Neurosci Abstr 1989;15:44.

[23] Perlman JM, Volpe JJ. Movement disorder in premature infants with severe broncho-pulmonary dysplasia: A new syndrome. Pediatrics 1989;85:215-8. 